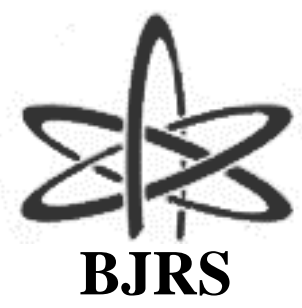

BRAZILIAN JOURNAL

$\mathrm{OF}$

RADIATION SCIENCES

07-02A (2019) 01-12

\title{
Dosimetric effectiveness in implants with distinct Ho- 166 seed distributions in a prostate model
}

\author{
Braga V.V.B. ${ }^{1}$ and Campos T. P. R. ${ }^{1}$ \\ ${ }^{1}$ Federal University of Minas Gerais/Department of Nuclear Engineering, 31270-901, Belo Horizonte, Minas Gerais, \\ Brazil \\ vitoriabraga06@gmail.com,tprcampos@yahoo.com.br
}

\begin{abstract}
Currently, there is a need to produce new therapeutic techniques for the treatment of prostate tumors, considering the high incidence of the disease and significant morbidity rates associated with surgery and radiotherapy. Simulations in brachytherapy produce essential information about the efficiency and dosimetric efficacy compared to other techniques. This study estimated the efficiency of dosimetry by parameters of merit generated from volumetric distributions of absorbed doses simulating two spatial distributions of Ho-166 seeds in a prostate model. A computer voxel model was developed, using the SISCODES (Computational System for Dosimetry by Neutrons and Photons by Stochastic Methods Applied to Radiology and Radiotherapy) code. The virtual model reproduced a cubic box, filled with muscle equivalent tissue (TE), in which a $5 \mathbf{c m}$ diameter sphere with TE-prostate was positioned $2 \mathrm{~cm}$ from the air-interface. Two Ho-166 seed distributions were employed with distinct pitches: 9 and $10 \mathrm{~mm}$, with same distance between seed of $8 \mathrm{~mm}$ in a fillet (needle). The MCNP5 code generated the energy deposited per unit mass in each voxel. The spatial dose distributions were obtained for each of the seed distributions. The following parameters-of-merit were evaluated: maximum dose values and histograms. The parameters were compared between the two simulated groups. It was possible to evaluate the most appropriate distribution to the prostate brachytherapy, which has been shown to be a function of the injected seed activity.
\end{abstract}

Keywords: prostate cancer, brachytherapy, Ho-166 seeds.

ISSN: 2319-0612

Accept Submission: 2018-10-29 


\section{INTRODUCTION}

Brachytherapy is a term used to describe a short-range radiation treatment provided by small sealed radionuclide sources. Sealed sources are positioned directly within or close to the target volume [1]. The dose is continuously deposited either over a short period of time (temporary implants) or over the lifetime of the radionuclide (permanent implants). The dosimetric advantage of brachytherapy compared to external beam radiotherapy is the possible improvement of the dose distribution in the target volume, thereby obtaining a more bounded volume versus dose. The disadvantage is that brachytherapy can be used only in cases in which the tumor is well confined and relatively small. Several aspects should be considered when brachytherapy treatments are performed. The most important is how the sources are positioned relative to the treatment volume.

Prostate cancer, among Brazilian men, is the second most lethal cancer, according to the National Cancer Institute [2]. Considering the high incidence of this disease and the significant morbidity rates associated with the current therapeutic methods, it is necessary to improve the radiotherapy techniques for the prostate tumors. I-125 radionuclide is often used in metal sealed seeds for permanent prostate brachytherapy implants. It has a half-life of 59.9 days and emits photons with $27 \mathrm{keV}$ energy, among others X-rays [3]. When used as monotherapy the prescribed prostate dose is high up to 145 Gy.

Other radioactive seeds have been suggested to prostate brachytherapy. Ho-166 seeds have been investigated by Nogueira and Campos [4,5,6], Valente and Campos [7], Valente et. al. [8], Diniz et. al. [9] and Campos et. al. [10].

Ho-166 is produced by the activation of Ho-165 in the interactions with thermal and epithermal neutrons. Ho-166 radionuclide decays by emission of $\beta^{-}$particles, with a half-life of $26.8 \mathrm{~h}$, transforming to the stable Er-166 nuclide. $\beta^{-}$emitted particles have maximum energy of $1855 \mathrm{keV}$ and average energy of $665 \mathrm{keV}$ [11]. In the Ho-166 decay, $\gamma$-emissions, of $80.57 \mathrm{keV}$ and $1379 \mathrm{keV}$ [11] and X-rays [11] with distinct yields are also emitted. Dose distribution around the seed depends on the physical properties of the radioisotope, including its activity, geometric seed configuration, mass density of the source materials and presence or not of an encapsulation [12]. 
Generation of dosimetry data in brachytherapy with Ho-166 seeds will allow advances in the knowledge of this technique. It is expected to launch such technology as an alternative to conventional I-125 brachytherapy, with consequent improvement in the quality of life of the patients. Computational simulation by Monte Carlo method (MC) has been used to calculate absorbed dose and effective dose in radiology and radiotherapy [13,14,15]. It is also used in comparative studies involving computational and experimental dosimetry $[16,17]$. In order to calculate the absorbed or effective dose, it is necessary to elaborate a virtual segmented model, or calling voxel model in which voxel is a set of volumetric image elements covering a three-dimensional space. It is worth mentioning that voxel phantoms constitute a virtual representation of a patient $[18,19]$. The Monte Carlo technique accompanies each of the primary or secondary particles, generated by a radioactive source, during its emission until its disappearance in some terminal event, such as absorption, scattering and escaping out the system.

The present work aims to estimate the efficiency of dosimetry by parameters-of-merit generated from volumetric distributions of absorbed doses simulating various spatial distributions of Ho-166 seeds in a prostate model.

\section{MATERIALS AND METHODS}

A virtual simulator was created, reproducing a $9 \mathrm{~cm}$ side acrylic cubic box filled with equivalent muscle tissue (TE-muscle), containing a sphere of $5 \mathrm{~cm}$ diameter of prostate equivalent-tissue (TEprostate), positioned on the $\mathrm{Z}$ axis $2 \mathrm{~cm}$ away from the surface (air-muscle interface). This simulator was implemented in the computational system SISCODES [20] and MCNP.

Two pre-plans were considered. The prostate was the prescribed target volume - PTV. Two spatial seed distributions were tested. Due to symmetry, the simulation met the XY quadrants, with X-axis positive. The two spatial distributions present a set of 40 seeds in the prostate in a half space $(X>0)$, consisting of 8 fillets (linear set of seeds in the Z-direction), with vertical spacing of $8 \mathrm{~mm}$ between seeds in each fillet (Figure 1). The fillets were distributed in the XY plane in the regular rectangular reticulated form containing four fillets each. A $10 \mathrm{~mm}$ fixed space was defined in the medium half 
of the prostate, due to the presence of urethra and ejaculatory ducts that are present in the central part of the prostate, defined by the YZ-plane in our model.

In the rectangular cross-section in XY, an equidistant space of $9 \mathrm{~mm}$ and $10 \mathrm{~mm}$ between the set of rectangular fillets was assumed. Fillets started on the surface of the prostate gland. Due to the spherical surface of the prostate model, the external fillets were placed $4 \mathrm{~mm}$ deep in relation to the internal ones ( $5 \mathrm{~mm}$ far the middle-plane), allowing different z-position between seeds of distinct fillets in relation to the level of the XY plane. The system was replicated computationally, obeying the symmetry in the $\mathrm{XZ}$ plane, thus totaling 80 implanted seeds. Each distribution was exported from the SISCODES code to the MCNP code. The two distributions are not considered the optimized one to fulfill the maximum dose on the prostate sphere; but they are a chosen group to have the dosimetry compared between them.

Figure 1: Distribution of the fillets in an arbitrary XZ-plane and respective pitch.

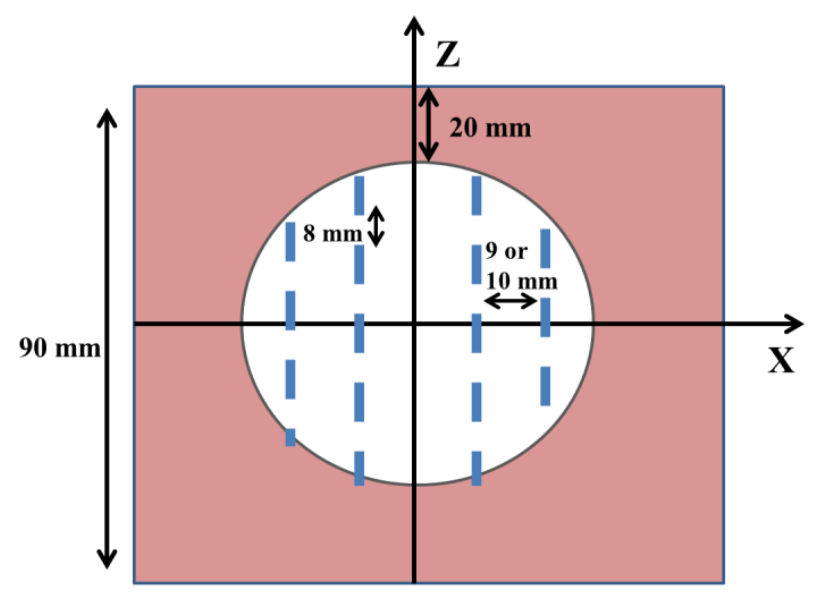

Discrete X-ray, Auger and gamma-ray emission sources and continuous beta-emission distributions (Figure 2) from the Ho-166 seed were evaluated and established. The code was run for the four types of emitting-sources. Auxiliary programs were created to simulate these distributions in the MCNP-v5 code and manipulated the data, with the help of the SISCODES computer system. These programs simulated and added the dose distribution provided by electrons, photons and X-rays, obeying their respective spatial and energy distributions, and emission probabilities. The spatial distribution of the Ho-166 emissions defined by seed-source, represented by a cylindrical geometry 
of $1.6 \mathrm{~mm}$ length and $0.5 \mathrm{~mm}$ diameter, was taken into account. The all ceramic seed material and the TE compositions were considered. The spatial dose distributions for each component and total were generated and plotted in images, normalized from 0 to $100 \%$ for their respective maximum doses, corresponding to their respective positions (beta, gamma or X-ray). The dose volume histograms (DVH) for each component and the total were generated showing how much of the PTV received from a certain dose.

\section{RESULTS AND DISCUSSION}

The spatial distributions of both the partial and the total doses were normalized through the maximum doses. For example, the maximum doses used in the normalizations for the $9 \mathrm{~mm}$ distribution are shown in Table 1, with respective emission's percentages of their respective components in relation to the normalized emission spectra.

Table 1: Percentage of emissions of each component, and maximum doses obtained in each simulation, referring to each emission component.

\begin{tabular}{lcc}
\hline \multicolumn{1}{c}{ Components } & $\begin{array}{c}\text { Percentage of } \\
\text { Yield per 100 }\end{array}$ & $\begin{array}{c}\text { Maximum dose } \\
(\mathrm{MeV} / \mathrm{g})\end{array}$ \\
\hline Gamma-ray & 8 & 0.0004675 \\
X-ray & 17 & 0.0050276 \\
Beta and & & 0.0083060 \\
Auger Electrons & 100 & \\
\hline
\end{tabular}

The partial normalized dose distributions for the photons, conforming to the two pitches, are presented in Figure 2 and Figure 3. 
Figure 2: Comparative partial normalized dose distributions from gamma-ray emissions taken on the $X$-axis, plane YZ, for 9 and 10 pitches.

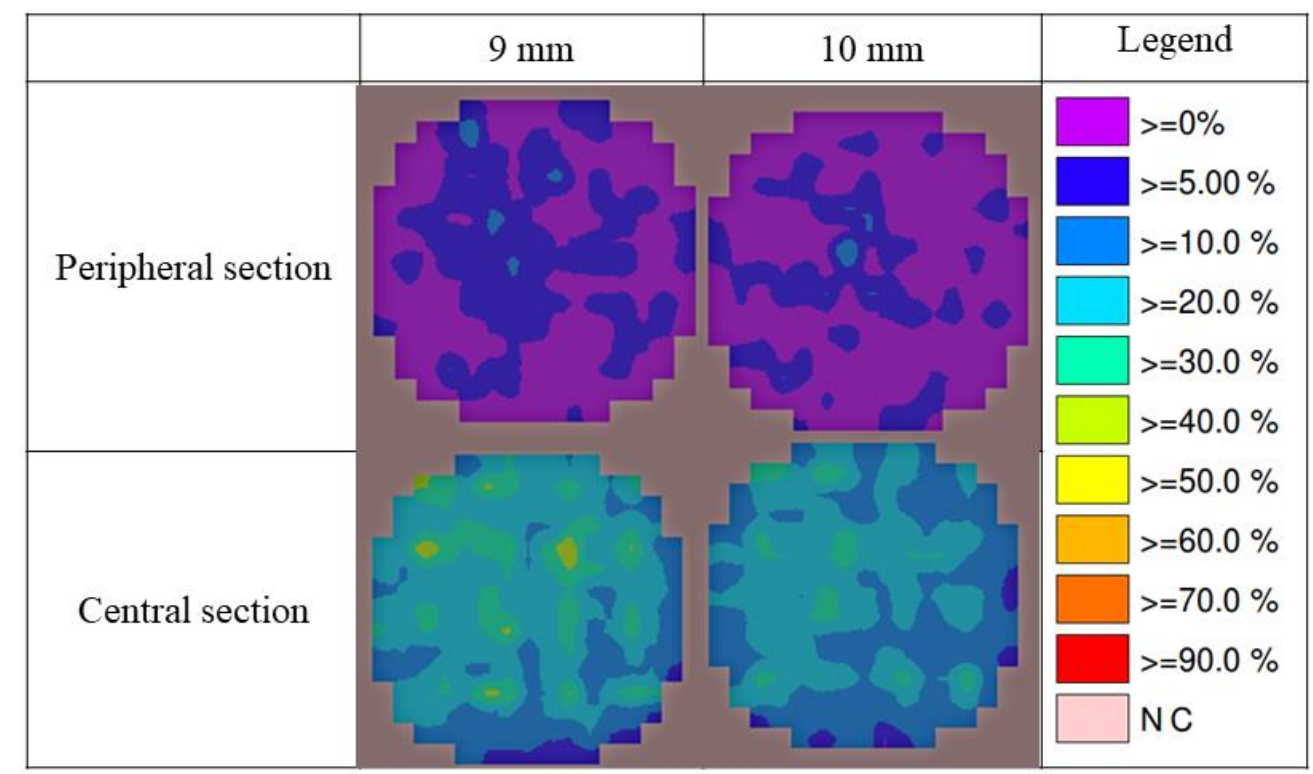

Figure 3: Comparative partial normalized dose distributions derived from X-ray emissions taken on the $X$-axis, plane YZ, for 9 and 10 pitches.

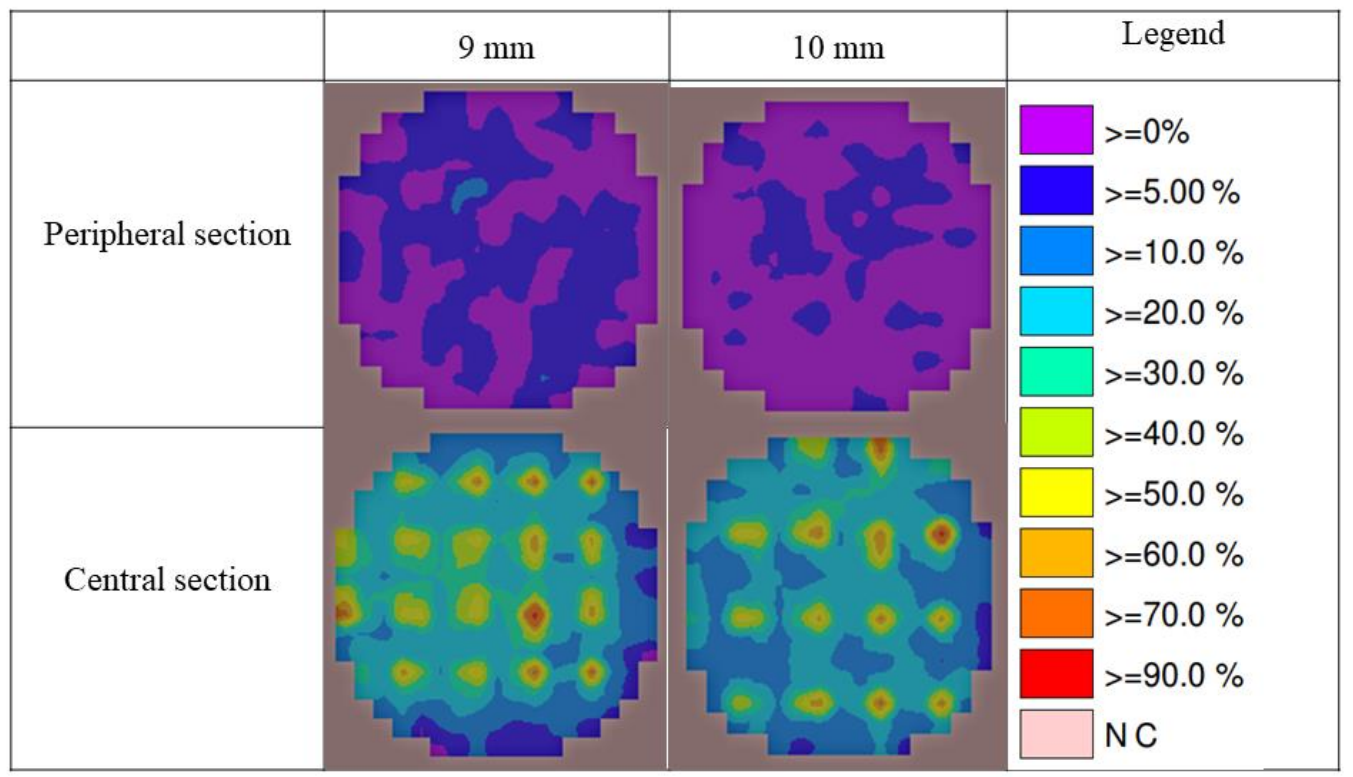


As shown in Figure 3 and 4, the partial dose distributions of gamma-rays and X-rays, as expected, a well-distributed over the plane YZ. Hot regions were found in the seed geometric distribution for Xray emissions. The total dose distributions are shown in Figure 4.

Figure 4: Comparative dose distributions from the dosimetric sum related to all emissions, taken on the plane $Y Z$, cross-section at $X$-axis, and plane $Z X$, cross-section at $Y$-axis, with a distance of $3 \mathrm{~cm}$ from origin, at the middle of the distance of two groups of filets, to 9 and 10 mm pitches.

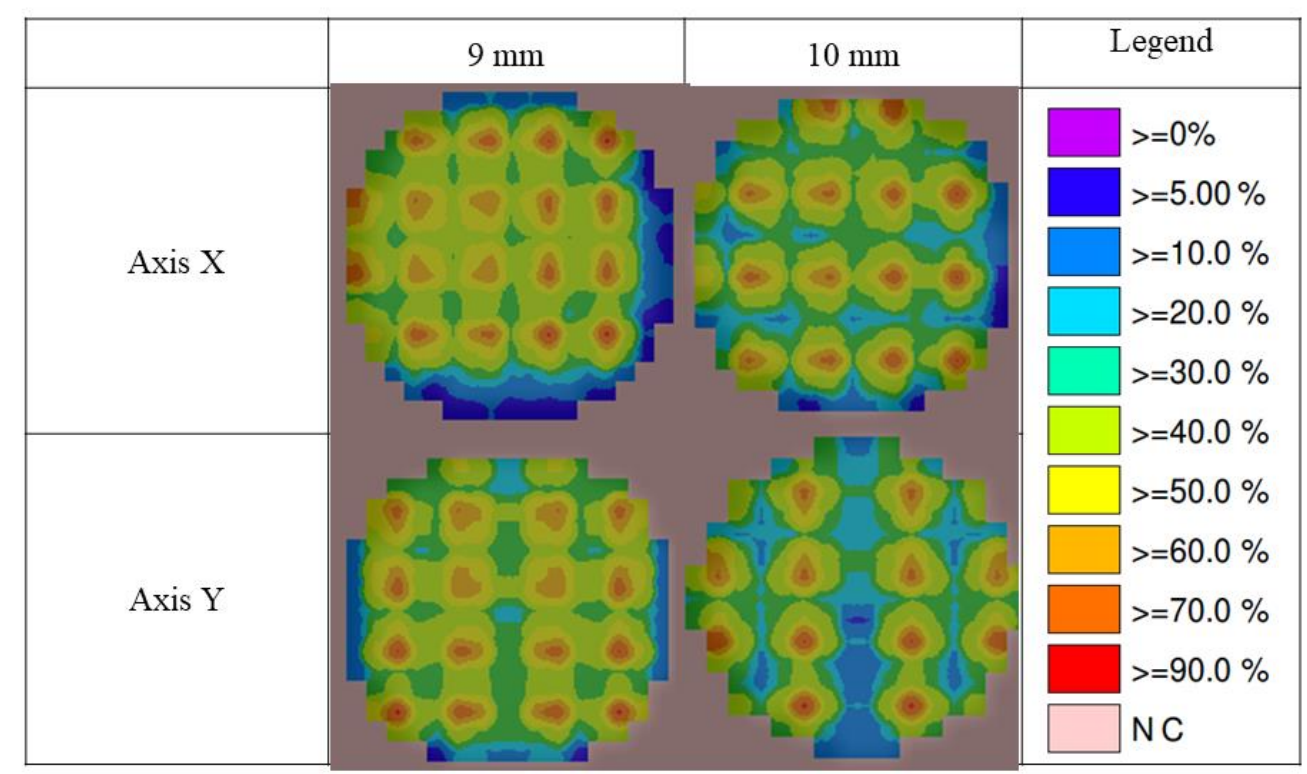

The maximum doses found for the $9 \mathrm{~mm}$ and $10 \mathrm{~mm}$ pitches were $0.330389 \mathrm{MeV}$ and 0.384235 $\mathrm{MeV}$, respectively. The $9 \mathrm{~mm}$ distribution resulted in a good overlap of the PTV with a prescribed dose of $30 \%$ of the total percentage-normalized dose equal to $145 \mathrm{~Gy}$. The $10 \mathrm{~mm}$ distribution also presented a good overlap of the PTV with a prescribed dose of $10 \%$ of the total percentagenormalized dose equal to 145 Gy. Indeed, dose into the PTV is higher than the prescribed dose.

For a representation of the percentage of the volume that received a dose equal to or greater than the prescribed dose, we used the cumulative dose versus volume histograms - DVH. The DVH to the seed distributions of 9 and $10 \mathrm{~mm}$ were presented in Figure 5 and 6, respectively. In these DVHs, one found the dosimetric comparisons between the emission-components. 
Figure 5: Cumulative dose versus volume histograms for the 9 mm distribution.

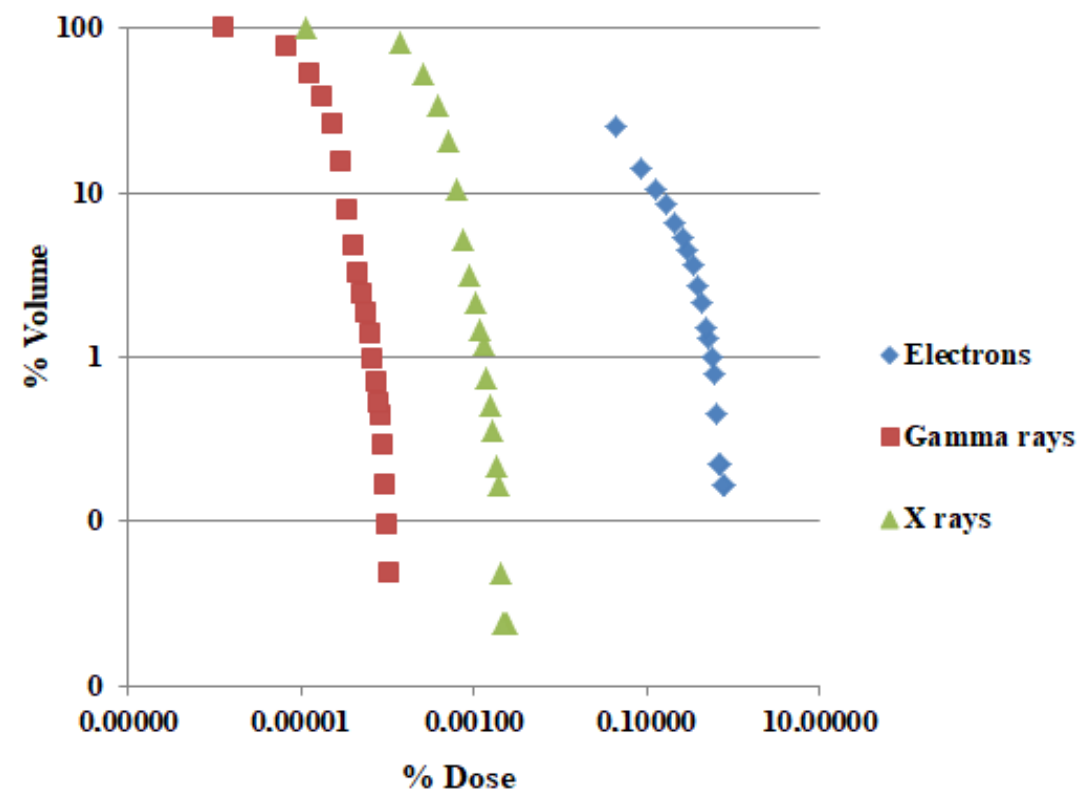

Figure 6: Cumulative dose versus volume histograms for the $10 \mathrm{~mm}$ distribution.

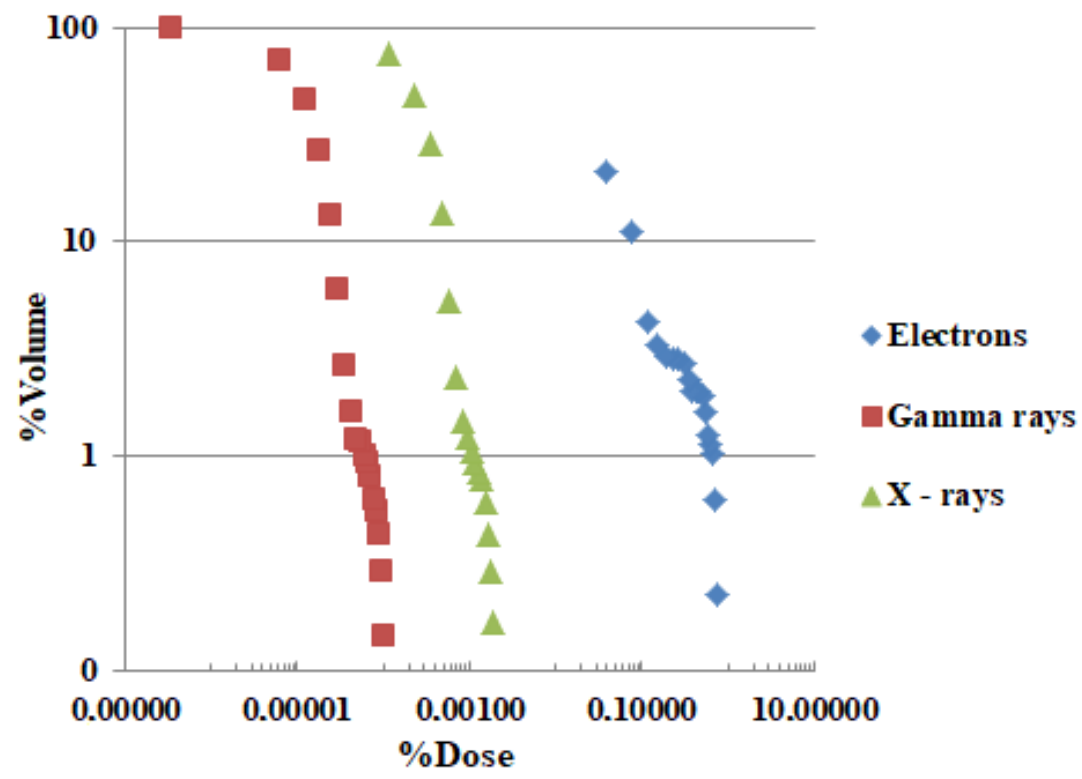

Can observe that among the dose-profiles the electron component held the most relevant volume versus dose in both the $9 \mathrm{~mm}$ and $10 \mathrm{~mm}$ distributions. The advantage in the dose offered by 
electrons is that their dose is confined near the seeds, due to their higher energy deposition in a short range. Thus, the dose distributed in the organs at risk can be much lower than other gamma emission sources. In the case of iodine-125 seed, most of the dosage is provided by low-photons and they have a long reach, as demonstrated by Trindade and Campos study [21]. Thus, for I-125 seed distribution at the human prostate, a considerable dose is deposited in the trabecular pubic bone outside prostate tissue, as shown [21].

The cumulative DVH plots of the electron dose profiles for the $9 \mathrm{~mm}$ and $10 \mathrm{~mm}$ pitches are shown in Figure 7.

Figure 7: Comparison of DVHs of the two distributions.

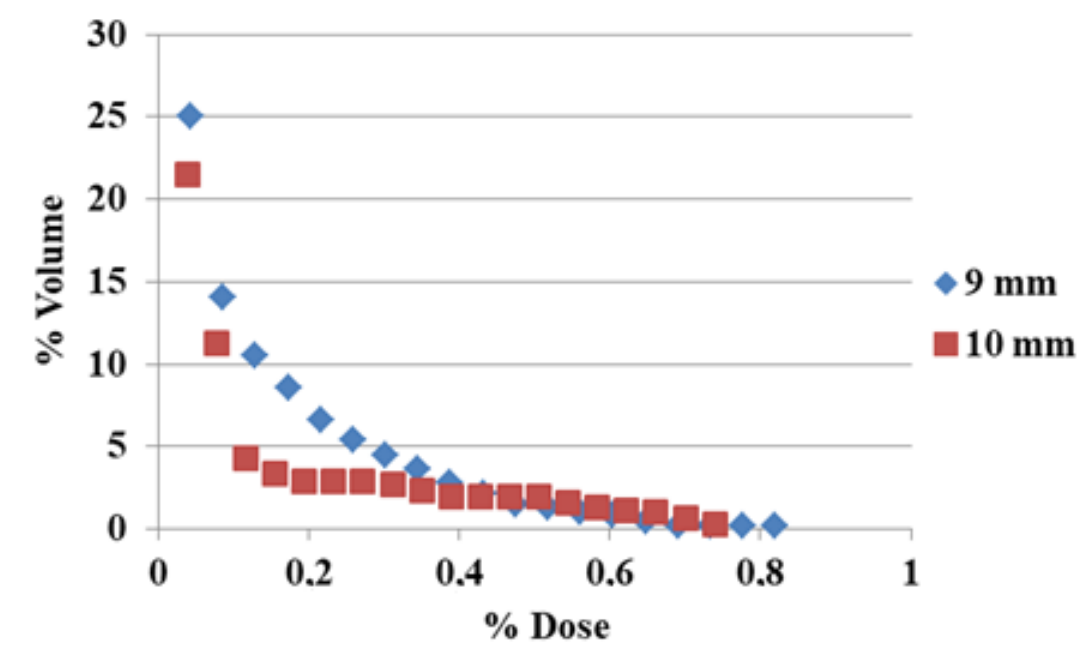

The pitch of $9 \mathrm{~mm}$ presented $0.0432 \%$ of the prescribed dose in $25 \%$ of the volume; while the 10 $\mathrm{mm}$ presented $0.0389 \%$ of the expected dose in $21 \%$ of the volume. Thus, the pitch of $9 \mathrm{~mm}$ provides a larger dose to a larger volume, thus such pitch seems more suitable. Such distribution was not optimized since the PTV was considered to be the whole prostate volume while the seed distribution did not cover all prostate spheres. The distribution held 16 fillets in a $4 \mathrm{x} 4$ matrix only. In these cases, a peripherical volume of the sphere was not considered.

The initial seed-activities required for each distribution in order to reproduce the prescribed dose on the PTV were evaluated. The $9 \mathrm{~mm}$ and $10 \mathrm{~mm}$ pitch seed-distributions required $1.5 \mathrm{mCi}$ and 3.8 $\mathrm{mCi}$ per seed activity, respectively. As expected, a greater initial activity is required for the $10 \mathrm{~mm}$ distribution and lower for $9 \mathrm{~mm}$. Such activities can be produced at the periphery of a TRIGA 
(Training, Research, Isotopes, General Atomic) type reactor in CDTN - Centro de Desenvolvimento de Tecnologia Nuclear - for $8 \mathrm{~h}$ operation, as an example.

\section{CONCLUSION}

The two $9 \mathrm{~mm}$ and $10 \mathrm{~mm}$ pitch-distributions provided a good overlap covering the PTV with a suitable dose, offering a prescribed percentage-normalized dose at least $30 \%$ to $9 \mathrm{~mm}$ pitch and $10 \%$ to $10 \mathrm{~mm}$ pitches of the maximum dose. The DVHs showed that the most relevant dose was offered by the electrons, which hold a short range and thus a lower dose deposition in organs at risk, out of the PTV. The higher dose versus volume was found in the $9 \mathrm{~mm}$ pitch distribution.

\section{ACKNOWLEDGMENT}

We thank the National Nuclear Energy Commission (CNEN) for the support through a doctora scholarship. We are thankful to CNPq for the support through the Rebrat-SUS-2013 project and to the Department of Nuclear Engineering of UFMG, where the work has been developed. We thank the institutional support of CNPq, CNEN, FAPEMIG and CAPES.

\section{REFERENCES}

[1] PODGORSAK, E. B. Radiation oncology physics a handbook for teachers and students, International Atomic Energy Agency, Vienna, 2005.

[2] INCA, Instituto Nacional do Câncer. INCA BR, 2017. Available at: <http://www2.inca.gov.br/wps/wcm/connect/cancer/site/oquee>. Last accessed: 11, July. 2017. [3] GRIMM P.D.; BLASKO J.C.; SYLVESTER J.E., M.D.; MEIER, R.M.; CAVANAGH W. 10year biochemical (prostate-specific antigen) control of Prostate cancer with 125-I brachytherapy, Int J Radiat Oncol Biol Phys, v. 51, p. 31-40, 2001. 
[4] NOGUEIRA L.B.; CAMPOS T.P.R. Nuclear chatacterization and investigation of radioactive bioglass seed surfaces for brachytherapy via scanning electron microscopy. J of Sol-Gel Science and Technology, v. 58, p. 215-258, 2011.

[5] NOGUEIRA, L.B.; CAMPOS, T.P.R. Radiological response of ceramic and polymeric devices for breast brachytherapy. Applied Radiation and Isotopes, v.70, p. 663-669, 2012.

[6] NOGUEIRA L.B.; CAMPOS T.P.R. Synthesis, chemical characterization and radiological response of Ho and HoZr bioglass seeds. J of Sol-Gel Science and Technology, v. 77, p. 688-698, 2016.

[7] VALENTE, E.S.; CAMPOS, T.P.R. Gamma spectrometry and chemical characterization of ceramic seeds with samarium-153 and holmium-166 for brachytherapy proposal, Applied Radiation and Isotopes, v.68, p. 2157-2162, 2010.

[8] VALENTE, E.S.; CUPERSCHMID, E.M.; CAMPOS, T.P.R. Evaluation of hela cell lineage response to $\beta$ radiation from Holmium-166 embedded in ceramic seeds. Brazilian Archives of Biology and Technology, v. 54, p. 957-964, 2011.

[9] DINIZ, M.F.; FERREIRA, D.M.; WANDERSON, G.L.; PEDROSA, M.L.; SILVA, M.E.; ARAUJO, S.A.; SAMPAIO, K.H.; CAMPOS, T.P.R.; SIQUEIRA, S. L. Biodegradable seeds of holmium don't change neurological function after implant in brain of rats. Reports of Practical Oncology \& Radiotherapy, v. 22, p. 319-326, 2017.

[10] CAMPOS, T.P.R.; NOGUEIRA, L.B.; TRINDADE, B.; CUPERSCHMID, E.M. Dosimetric intercomparison of permanent Ho-166 seed's implants and HDR Ir-192 brachytherapy in breast cancer. Reports of Practical Oncology \& Radiotherapy, v. 21, p. 240-249, 2016.

[11] LNHB, Laboratoire National Henri Becquerel. France, 2017. Available at: <http://www.nucleide.org/DDEP_WG/Nuclides/Ho-166_tables.pdf>. Last accessed: 27, May. 2017. [12] PEREZ, C.A. Technical Basis of Radiation Therapy, Springer, 2006. p. 275.

[13] BENI, M. S.; NG C.Y.P, KRSTIC D., NIKEZIC D., YU K.N. Conversion coefficients for determination of dispersed photon dose during radiotherapy: NRUrad input code for MCNP. PloS one, 12.32017

[14] TAGHAVI, R.; MIRZAEIET H. R.; AGHAMIRI S.M.R.; HAJIAN P. Calculating the absorbed dose by thyroid in breast cancer radiotherapy using MCNP-4C code. Radiation Physics and Chemistry, v.130, p. 12-14, 2017. 
[15] HADAD, K.; MAHDI S.; BANAFSHEH Z. Voxel dosimetry: Comparison of MCNPX and DOSXYZnrc Monte Carlo codes in patient specific phantom calculations. Technology and Health Care, v.25, p. 29-35, 2017.

[16] PAPPAS, E. P., ZOROS E., MOUTSATSOS, A., PEPPPA, V., ZOURARI, K., KARAISKO, P., PAPAGIANNIS, P. On the experimental validation of model-based dose calculation algorithms for 192Ir HDR brachytherapy treatment planning. Physics in Medicine and Biology, v. 62, p. 4160, 2017.

[17] MOUNTRIS, K. A., BERT, J., NOAILly, J., AGUILERA, R.A., VALERI, A., PRADIER, O., SCHICK, U., PROMAYON, E., BALLESTER, M.A.G. Modeling the impact of prostate edema on LDR brachytherapy: a Monte Carlo dosimetry study based on a 3D biphasic finite element biomechanical model. Physics in Medicine and Biology, v.62, p. 2087-2102, 2017.

[18] FERREIRA, C. C.; GALVÃO, L. A.; VEIRA, J. W.; MAIA, A. F. Validação de um modelo computacional de exposição para dosimetria em tomografia computadorizada. Revista Brasileira de Física Médica, v. 4 , p. 19-22,2010.

[19] X-5 MONTE CARLO TEAM. MCNP - A general Monte Carlo N-Particle transport code, v. 5.: Los Alamos National Laboratory, Los Alamos, NM, 2003.

[20] TRINDADE, B. M. Desenvolvimento de sistema computacional para dosimetria em radioterapia por nêutrons e fótons baseado em método estocástico SISCODES. Belo Horizonte, MG: Departamento de Engenharia Nuclear, Universidade Federal de Minas Gerais, 2004.

[21] TRINDADE, B. M.; CHRISTOVÃO, M. T.; TRINDADE, D. F. M. ; FALCÃO, P. L. ; CAMPOS, T. P. R. . Comparative dosimetry of prostate brachytherapy with I-125 and Pd-103 seeds via SISCODES/MCNP. Radiologia Brasileira, v. 45, p. 267-272, 2012. 